\title{
Collaboration Among Project Participants Towards Sustainable Construc- tion - A Hong Kong Study
}

\author{
L Y Shen ${ }^{1}$, S C Song ${ }^{2}$, J L Hao ${ }^{1}$ and Vivian W Y Tam* \\ ${ }^{1}$ Department of Building and Real Estate, The Hong Kong Polytechnic University, Hong Kong; ${ }^{2}$ ShueYan University, \\ Hong Kong; ${ }^{3}$ Griffith School of Engineering, Griffith University, PMB 50 Gold Coast Mail Centre, QLD 9726, Australia
}

\begin{abstract}
This paper shows that management has dominant influences on sustainable construction practices in Hong Kong. Improving construction business performance along with sustainable development is widely appreciated. Major factors affecting sustainable performance are social, economic and environmental considerations. This has led to the development of various management approaches to advise construction participants on how to improve their performance with a view of bringing satisfactory project sustainable performance across the full construction project life cycle. In particular, methods to improve environmental performance in construction have been extensively investigated. Recent studies have presented methods to mitigate barriers in implementing environmental management in construction. However, these studies are driven by examining the nature of construction activities rather than the management strategies that drive sustainable practice. This paper examines management-related reasons which hinder the implementation of sustainable construction in practice. A construction project participant collaboration framework is developed to improve communication among project participants towards sustainable construction implementation. Future opportunities and challenges are identified for various parties engaging in construction activities to provide effective contributions to sustainable development. This research work also provides useful references in examining sustainable construction practice.
\end{abstract}

\section{INTRODUCTION}

Construction activities refer to a wide range of activities, such as building work, hydraulics, airports, railways, highways, bridges, dredging harbours, dock-work, sewage treatment facilities, tunnelling and demolition activities. Sustainable construction refers to the practice by which construction activities contribute to sustainable development. It is a set of processes by which a profitable and competitive industry delivers built assets $[1,2]$ : i) to enhance quality of life and to offer customer satisfaction; ii) to offer flexibility and potential to cater for user changes in the future; iii) to provide and to support desirable natural and social environments; and iv) to maximize the efficient use of resources.

Sustainable development is typically defined as to meet basic needs of the public and to extend opportunities to satisfy their aspiration for a better life without compromising abilities of future generations to meet their own needs [3]. It promotes the balance of environmental protection, economic development and social development.

Sustainable assessment is a collective term for measurement and analysis of criteria, which are either having direct or indirect environmental impacts $[4,5]$. It is also defined by Kuhre's study as a continuous monitoring process, which is applied to evaluate companies' sustainable performance [6]. Sustainable assessment has been broadly used in different business sectors. It can provide reliable, objective and

*Address Correspondence to this Author at the Griffith School of Engineering, Griffith University, PMB 50 Gold Coast Mail Centre, QLD 9726, Australia; Tel: 61-7-5552-9278; Fax: 61-7-5552-8065;

E-mail:v.tam@griffith.edu.au verifiable information on management about achievements of organisations' environmental objectives and targets, as well as fulfilling legislative regulations regarding environmental protection. Results from sustainable assessment can also help predicting future trends in environment-related development, which assist management in designing suitable environmental strategies for future projects [5, 7-9].

This paper aims to:

- examine various sustainable construction initiatives in Hong Kong;

- investigate different economic periods affecting sustainable construction implementation;

- examine methods improving sustainable construction;

- study opportunities and challenges in practising sustainable construction;

- develop a construction project participant collaboration framework; and

- provide recommendations improving sustainable construction practice in Hong Kong.

\section{Sustainable Construction Initiatives}

As construction activities are commonly considered as major contributors to negative environmental impacts, implementation of sustainable construction often focuses on improving environmental performance across a project's life cycle. Examples of sustainable construction initiatives in Hong Kong are identified as follows [10-20].

\section{Optimum Land and Space Use}

At the project planning stage, consideration is given to the optimum use of land and space. For example, there are 
many vacant factory buildings in Hong Kong. These existing buildings became vacant as a result of the move of manufacturing industries to Southern Mainland China. Suggestions have been put forward to refurbishing these existing buildings to apartments and hotels, thus improving their sustainable or adaptive reuse. Another planning initiative to improve their sustainable value is by properly restoring and protecting them. The local government has also suggested making effective use of underground space thus reducing above-ground traffic and pollution, thus improving the living environment.

\section{Improving the Living Environment}

In the project design stage, consideration is given to choose non-depletable and recyclable construction materials, for example, prefabrication and reusable formwork, thus to reduce ecological impacts in implementing construction projects. In recent years, the Hong Kong government has also introduced a tax reduction scheme to encourage provision of balcony areas and roof gardens. Air quality can then be improved in the living environment. The implementation of these schemes aims to provide healthy, safe and pleasant built facilities and surrounding environments.

\section{Environment-Friendly Construction Methods}

On-site construction activities cause air, noise, water and waste pollution. The Hong Kong government issues ordinances and regulations to control air, noise, water and waste pollution [21]. A summary of the ordinances and regulations is shown in Table 1. The government also recently introduced a construction waste disposal charging scheme to promote reduction of construction and demolition waste and use of recycled construction solid waste and components.

\section{Energy Saving in Building Life Cycle}

The Hong Kong government encourages reducing energy consumption in the building life cycle by promoting the use of building materials with less embodied energy, which is the energy used for producing construction materials and components. An example is to promote the adoption of local materials thus reducing energy consumption involved in transportation.

Energy in the natural environment exists in various typical formats such as natural gas, crude oil, coal and water. These fossil fuels and minerals are depletable and often converted into other forms of power such as electricity. In turn, this energy is used to extract and transport raw materials, to process materials, to fabricate construction components, to operate construction equipment and plants, and to operate built facilities.

\section{RESEARCH METHODOLOGY}

The major objective of this study is to examine various sustainable construction initiatives by referring to Hong Kong construction industry. The data used for analysis are mainly from public reports produced by Hong Kong government. The experience by the research team to the construction industry also contributed to the data generation and analysis in the study. In fact, one research member is a senior practitioner in Hong Kong construction industry. The data generation and analysis is largely based on the discus-
Table 1. Regulations and Ordinances Related to Construction Industry in Hong Kong [21]

\begin{tabular}{|l|l|}
\hline \multicolumn{1}{|c|}{ Regulations or Ordinances } & \multicolumn{1}{c|}{$\begin{array}{c}\text { Caption } \\
\text { (Cap.) } \\
\text { Number }\end{array}$} \\
\hline \hline $\begin{array}{l}\text { Air pollution control ordinance } \\
\text { Air pollution control (construction dust) } \\
\text { regulation } \\
\text { Air pollution control (smoke) regulations }\end{array}$ & Cap. 311 \\
- Air pollution control (open burning) regulation & \\
Air pollution control (dust and grit emissions) \\
regulations
\end{tabular}

sion within the research team. Team-orientated approach has been adopted throughout the study.

\section{ECONOMIC ISSUES AFFECTING SUSTAINABLE CONSTRUCTION IMPLEMENTATION}

The Hong Kong construction has experienced two different economic periods before and after the handover in 1997: i) a prosperous period in the early and middle 1990s; and ii) a recessive period between the late 1990 s and early 2000 s. Although the government has introduced sustainable policies and regulations, this study found that insufficient action was taken in implementing sustainable construction across both periods.

\section{Sustainable Construction Practice During the Economic Prosperous Period}

In the prosperous period, it could be more effective to promote sustainable construction measures than in the recessive time. However, it seems that the local government did not pay sufficient attention during the economy boom in the early 1990s. Increasing gross domestic products (GDP) and 
contributions of construction work to GDP during the main period of 1990s are shown in Table 2.

Table 2. Statistics of GDP and construction contribution in Hong Kong during 1992-1997 (in HK\$million) [22]

\begin{tabular}{|c|c|c|c|}
\hline & $\mathbf{1 9 9 2}$ & $\mathbf{1 9 9 3}$ & $\mathbf{1 9 9 4}$ \\
\hline \hline GDP & 805,082 & 927,996 & $1,047,470$ \\
\hline Construction & 62,232 & 56,226 & 59,710 \\
\hline & 1995 & 1996 & 1997 \\
\hline GDP & $1,115,739$ & $1,229,481$ & $1,365,024$ \\
\hline Construction & 65,611 & 74,901 & 81,629 \\
\hline
\end{tabular}

It appears to the research team that insufficient effort was contributed by both project clients and contractors in implementing sustainable construction measures during the construction boom. The discussions from the survey have revealed typical reasons for not implementing sustainable construction in the local industry.

1. There is an opportunistic culture in the construction industry, in particular in the private property sector, to make "quick" revenue when there is a good economic environment and market, and thus insufficient attention to environmental performance.

2. During the economic boom, there was high labour cost and low material cost. Therefore, there was a strong reluctance for business to invest management and labour resources to improve environmental performance.

3. Programmes promoted by the government are always late due to one reason or another which shows a growing culture of "decision but no action". This has sent a message to both construction professionals and the public that environmental considerations are not on the government agenda.

4. Comprehensive applications of multi-layered subcontracting arrangements present difficulties in effectively supervising on-site activities. Usually, there are three to four non-value-adding multi-layered subcontracting tiers in construction work. On site bottom-tier contractors cannot be provided with clear guidance and close supervision by main contractors, and is considered one of the major reasons resulting in poor environmental performance on site.

5. Environmental awareness issues among construction workers in the industry are low, worsened by the reluctance of senior management to commit resources to tackle environmental issues.

6. Despite numerous land reclamation programmes in the local industry, potential demand for a great amount of material, construction and demolition waste for this purpose has not been realized. The ever increasing amount of construction waste still presents the largest pollution component in the local region.

7. Principles of sustainable construction have not been sufficiently incorporated in feasibility study and design. De- sign parameters usually include building types, shapes, directions and materials, which often ignore environmental performance.

8. The government has no specific measures to encourage construction professionals in implementing sustainable construction practice. Although various regulations have been introduced, construction professionals find limited effectiveness without encouragement or incentives. It is suggested that incentive schemes should be implemented to achieve environmental improvement.

\section{Sustainable Construction Practice During the Recessive Period}

Having realized that Hong Kong is behind other countries in practising sustainable construction, the former Chief Executive of the Hong Kong Special Administrative Region (HKSAR) in 1999 brought sustainable development issues into in the Policy Address. He requested that every citizen, every business, every government department and bureau starts partnering to achieve sustainable development for Hong Kong. However, his address was not optimum because Hong Kong was in a recessive period, beginning with the Asian financial turmoil in late 1997. This economic recession also caused the downturn of construction businesses, which is evidenced by the statistics shown in Table 3 .

Table 3. Statistics of GDP and Construction Contribution in Hong Kong During 1997-2005 (in HK\$ Million) [22]

\begin{tabular}{|c|c|c|c|}
\hline & $\mathbf{1 9 9 7}$ & $\mathbf{1 9 9 8}$ & $\mathbf{1 9 9 9}$ \\
\hline \hline GDP & $1,365,024$ & $1,292,764$ & $1,266,702$ \\
\hline Construction & 81,629 & 79,007 & 70,941 \\
\hline & 2000 & 2001 & 2002 \\
\hline GDP & $1,314,789$ & $1,298,813$ & $1,276,757$ \\
\hline Construction & 79,599 & 80,702 & 73,223 \\
\hline & 2003 & 2004 & 2005 \\
\hline GDP & $1,273,893$ & $1,291,568$ & $1,382,052$ \\
\hline Construction & 70,295 & 66,280 & 59,266 \\
\hline
\end{tabular}

Although the HKSAR economy began to prosper in 2000 , good trends could not be continued as the world suffered adverse impacts from the Y2K network bubble in late 2000 and the "911" terrorist attack in 2001. Severe acute respiratory syndrome (SARS) caused the Hong Kong property market to collapse to its lowest point in 2003, although from 2004 onwards the economy has been recovering. But there is no improvement in construction activities, evidenced by decreasing figures seen in Table 3. A major reason for this is that there is the lack of major infrastructure projects since the beginning of year 2000.

Over the fourteen years (1992-2005) reported, GDP of Hong Kong has increased by about $71.67 \%$, whereas construction has declined by about $42.68 \%$ from its peak in 1997. Yet construction has contributed between $4.29 \%$ and $7.73 \%$ of GDP, with an average of about $5.86 \%$ over the period. This mismatch is the results of an overheated construction market in the early 1990s. 
During the interview discussions, the interviewees highlighted their difficulties in implementing sustainable construction during the recessive period:

1. There was a lack of resources including facilities and equipment available to implement sustainable construction on site due to very tight budget.

2. The local government and clients were not concerned with sustainable construction; rather lowering construction cost was their main project objective.

3. Project developers provided insufficient support for designers and contractors to implement sustainable construction to their projects, including financial and technical assistance.

4. As sustainable construction was still new in the local industry during this time, construction practitioners were using a "wait-and-see" attitude.

5. There were insufficient standards, specifications or guidelines provided by the government or private organizations to assist with sustainable construction implementation.

6. There was a lack of sustainable awareness by project stakeholders. The main goals for them were to lower project costs and shorten project duration, while sustainable construction involved high initial cost and potentially longer construction periods.

\section{METHODS TO IMPROVE SUSTAINABLE CON- STRUCTION}

The analysis in Section 0 suggests that there is still a pressing need to improve sustainable construction performance in the Hong Kong construction industry. From that, effective methods can be adopted. Various methods have been suggested by the previous research to effectively implement sustainable construction practice $[1,2,4-9,23$ 29]. In line with these developments, the HKSAR government has introduced certain measures for implementing sustainable construction over the years. In chronological order, these are:

- In 1980, major environmental ordinances and regulations, shown in Table 1, were enacted, to control environmental performance and to improve sustainable construction.

- In 1989, the government addressed environmental protection issues with the establishment of a framework for a comprehensive 10-year plan to reduce construction waste and other pollution problems, including a commitment to review its progress every two years.

- In 1995, the government launched a green manager scheme, requiring every government department appoints a green manager to manage environmental performance of individual organizations.

- In November 1998, the government launched its waste reduction framework plan, which aims to change waste treatment habits of the public.

- In February 2001 and 2002, the Building Department, Lands Department and Planning Department issued two
Joint Practice Notes entitled "Green and Innovative Buildings". The objective is to encourage the design and construction of buildings to adopt a holistic life cycle approach, to maximize the use of green building materials, to minimize the consumption of energy and to reduce construction and demolition waste.

- In February 2003, the Buildings Department issued a practice note for authorized persons and registered structural engineers entitled "use of recycled aggregate in concrete." This technical guideline can be applied to prescribed mix concrete (20P) and designed mix concrete (25D to $35 \mathrm{D})$ to adopt $100 \%$ and $20 \%$ recycled aggregate respectively.

- In May 2003, the Environment Transport and Works Bureau produced a circular (Ref: 15/2003) on "waste management on construction sites" that explained the implementation of the government's "waste management plan" and "pay for safety and environment scheme" for public construction projects.

- In 2004, the Civil Engineering Department commissioned a pilot recycling plant at Tuen Mun Area 38 to supply recycled aggregate to a number of public projects from 2004 to 2006.

- In December 2005, the government implemented a landfill charging scheme that charges those who dump their waste into public landfills, thereby encouraging contractors to recycle and to reuse construction waste.

In addition to the relevant ordinances, regulations and practice notes driving sustainable practice, private sectors should also be encouraged to implement an environmental management system (EMS) at an organizational level. This ensures that a company is continuously improving its environmental performance through identifying, minimizing, preventing and managing environmental impacts which may come from its business activities [30-32]. Therefore, risks of environmental violation are reduced by implementing an EMS. A typical EMS consists of four major areas, namely, environmental policy, organisational structure, environmental management programme, and audit of environmental performance. The EMS can be classified into a generic EMS and a corporate EMS. The generic EMS is designed to be adopted by any industry sector and generally developed as a commercial-available system. The corporate EMS is developed in-house to suit specific requirements of a company or a government organization. To guide establishing EMS, ISO 14000 provides a standard or sample that organizations can follow.

Principles of the ISO 14000 provide frameworks for the EMS. In construction practice, the ISO 14000 standard provides a benchmark of proper environmental management practice, so different organizations can have different specifications under the framework. The EMS defined in ISO 14001 emphasizes on more effective environmental ethics to project design, material selection, and transportation logistics throughout a product's life cycle. This standard provides a framework to achieve and to demonstrate a desirable level of environmental performance. The framework defines a management system to track environmental performance, to set pragmatic objectives, to develop consistent procedures and 
program initiatives, and to review progress for continuous improvement [33].

A typical advantage of implementing ISO 14001 is that the system provides a benchmark to implement an EMS. Management is required to demonstrate commitment to environmental management, which includes clearly setting environmental objectives and targets, provides adequate measures for responding environmental events and achieves the defined objectives and targets. Management should emphasize on pollution prevention rather than corrective action, and get all employees throughout the organization involved and communicated. An environmental culture should be cultivated within the organization, thus all staff can participate and help identify environmental problems, which in return increases efficiency in utilizing resources and energy to correct them. This leads to continuous improvement in the organization's environmental performance.

The ISO 14001 standard does not define any particular acceptable level of performance. Different organizations can define their own level of environmental performance by applying the ISO 14001 framework. But with the structured approach that the system provides, senior management can have clear procedures and specific actions in committing environmental liabilities. Well-planned strategies can enhance an organization to respond quickly to environmental events instead of hastily reacting to crises and surprises. Furthermore, construction waste and energy consumption during project processes can be reduced through a continuous process to improve environmental performance. Consequently, an organization's long-term profitability can be enhanced as its environmental competitiveness increases.

\section{OPPORTUNITIES AND CHALLENGES IN PRACTIC- ING SUSTAINABLE CONSTRUCTION}

The Hong Kong government is going to implement ambitious construction plans involving huge amounts of public infrastructure construction work in the coming years. The government has recognized the importance of infrastructure investment, and accordingly the importance of implementing sustainable construction practice. This is evidenced by a large number of initiatives. The finance secretary of the HKSAR indicated that the government wants to spend about HK $\$ 29,000$ million per year on construction over the next five years [34]. In 2004, the government launched strategies and procedures to promote sustainable development in the local territory by publishing a document called "the first sustainable development strategy for Hong Kong" [35]. In a policy address from the Chief Executive in 2006, it was stated that currently "Hong Kong development is hampered by insufficient investment and slow pace of public investment. I believe that in the days ahead, it will be important for the government to enhance communication with the business community, councils and environmental groups on development goals. Only in this way we can smoothly take forward our public investment programmes" [36].

In line with these initiatives, a substantial number of construction initiatives for Hong Kong have been specified in the booklet "Policy Agenda" attached to the 2006-2007 Chief Executive's Policy Address. These projects are in different categories according to their progression status al- though it is difficult to give detailed demarcation lines among them as infrastructure work often lasts for many years. Some of these works have been constructed, some are planned and ready for construction, and some are still in design or feasibility stage. Typical work among these categories is listed as follows.

Work undertaken and / or in construction includes:

- To provide a variety of infrastructure, resources and support services to the digital entertainment industry in Cyberport;

- To operate new job centres in Yuen Long and northern district areas;

- To assist the airport authority to expand intermodal connections between the airport and pearl river delta region;

- To implement measures enhancing the competitiveness of Hong Kong ports as recommended by a port master plan 2020;

- To expedite development of new cruise terminal facilities;

- To monitor and to develop marine police headquarters in Tsim Sha Tsui into a heritage tourism attraction in 2008;

- To monitor progress of the Lok Ma Chau Spur line to be commissioned in the first half of 2007 ;

- To develop the Kowloon southern link;

- To prepare commissioning of the Hong Kong western corridor to the Shekon boundary crossing in the middle of 2007; and

- To ensure the disposal of a surplus home ownership scheme beginning in 2007.

Work planned and for implementation includes:

- To replace a civil aviation department with an air traffic control system;

- To develop new civil aviation department headquarters on the airport island;

- To map out long-term developments of the electricity market;

- To coordinate various major tourism infrastructure projects including Disneyland, Wetland Park and Ngong Ping 360;

- To plan a Aberdeen tourism project to complement the Ocean Park redevelopment;

- To enhance the Lei Yue Mun waterfront;

- To develop a piazza in Tsim Sha Tsui;

- To implement a design-and-build Tamar project; and

- To pursue preparatory work for the Hong Kong-ZhuhaiMacao bridge.

Work in design includes:

- To reduce coverage of frontier closed areas for development;

- To plan widening of town centre sections; 
- To improve an expressway section of Tuen Mun road;

- To evaluate the eastern corridor at Liantang/Heung Yuen Wai control point and new crossing;

- To determine optimal timing for the container terminal 10 construction in port cargo forecast;

- To assess ecology on northwest Lantau for development of the container terminal 10;

- To implement a Lantau logistics park project for subsequent zoning and reclamation;

- To proceed a combined project of the Hong Kong section of a Guangzhou-Shenzhen-Hong Kong express rail link;

- To plan Shatin to central link and the western island line;

- To assess the viability of the southern island line;

- To update a Lantau concept plan providing fresh impetus for Hong Kong economic development; and

- To coordinate the timetable for railway property developments.

According to the plan described in the 2005-06 Budget of the Hong Kong, there would be HK\$29 billion investment from the Government for the period 2006-2010. From Table 4, entitled Major Capital Projects to Begin in 2007-08, the government has commenced 14 projects for infrastructure and support with annual budget of HK\$22,425 million, 5 projects for education (HK\$3,138 million), 2 projects for health (HK\$3,063 million), 3 projects for security (HK\$1,824 million), 3 projects for community and external affairs (HK $\$ 1,682$ million) and 2 projects for environmental and food (HK\$1,037 million). It is envisaged that the government will spend HK\$33.1 billion in 2007-08, even more than HK\$29 billion as planned.

The implementation of the above public construction work can certainly revitalize the Hong Kong construction industry, which can stimulate those in the private sector in return. Thus the time to implement sustainable construction practice in the local construction industry is ripe.

\section{DEVELOPMENT OF A CONSTRUCTION PROJECT PARTICIPANT COLLABORATION FRAMEWORK}

Various methods and policies identified in the previous sections are important and should be encouraged for their application. However, from the interview discussions, the interviewees argued that there is a major gap in promoting these measures. Existing methodologies focus on solutions to solve particular technical issues, such as waste, air pollution, and ecological impacts. Solutions are also available for implementing management activities, such as establishing EMS using ISO standard procedures. However, one of the interviewees noted that neither the establishment and operation of an EMS nor the introduction of policies and regulations would themselves necessarily result in the improvement of environmental performance. Another interviewee explained that collaboration among various project participants provides insufficient attention. In fact, implementing construction activities normally involves multiple organizations, including government departments, project owners, contrac-
Table 4. Major Capital Projects to Begin in 2007-08 [37]

\section{Infrastructure and Support (HK\$22,425 million)}

- Construction, improvement and widening of Pol Oi Interchange/Sha Tin Trunk Road T4/Tuen Mun Road Tsing Tin Interchanges/Tuen Mun Road L18A/Ha Tsuen Section of Ping Ha Road

- Customs Headquarters Building

- Demolition of buildings and structures in Kwai Chung, Kennedy Town and Cheung Sha Wan

- Development at Anderson Road (site formation and associated infrastructure works)

- Drainage improvement works on Northern Hong Kong Island, in East and West Kowloon and in New Territories

- Engineering infrastructure works for Pak Shek Kok development

- Improvement and extension of pedestrian subway system and footbridge in Kwai Chung and Tsuen Wan

- Improvement to Hong Kong Central mid-level and high level areas water supply

- Provision and replacement of traffic control, surveillance and information dissemination facilities

- Provision and uprating of salt water supply for Northwest New Territories/Northwest Kowloon

- $\quad$ Replacement and rehabilitation of water mains, stage 2

- Retrofitting of noise barriers on Tsing Tsuen Bridge, Tseung Kwan O Road and Yuen Shin Road

- Site formation for school development at Aberdeen Reservoir Road, Aberdeen

- Tamar Development

Education (HK\$3,138 million)

- Construction, extension, redevelopment and repositioning of primary, secondary and special schools

- Headquarters and onscreen marking centres of the Hong Kong Examinations and Assessment Authority

- Multi-media Building - stage 2, The City University of Hong Kong

- New campus at Tiu Keng Leng for the Vocational Training Council

- 1500 -place student hostel, The Chinese University of Hong Kong

Health (HK\$3,063 million)

- $\quad$ Prince of Wales Hospital - extension block

- $\quad$ Redevelopment of Caritas Medical Centre, phase 2

Security (HK\$1,824 million)

- Government Complex at Mei Lai Road

- Junior Police Officers' married quarters in Area 44, Tuen Mun

- Redevelopment of Lo Wu Correctional Institution

Community and External Affairs (HK\$1,682 million)

- Improvement works to the sports venues for the 2009 East Asian Games

- Provision of open space and recreation grounds in Ma On Shan, Kwai Chung, Tsing Yi, Sheung Shui, Tsuen Wan, Wong Tai Sin and Ap Lei Chau

- $\quad$ Renovation of libraries - phase 2 works

Environment and food (HK\$1,037 million)

- Conversion of aqua privies into flushing toilets

- $\quad$ Northern District, Port Shelter and outlying islands sewerage 
tors, architects, consultants, material and equipment suppliers, and various specialist tradesmen. The effectiveness of applying various methods and regulations for sustainable construction practice is determined by the effectiveness of the level of collaboration among project participants. From that, by examining roles of individual project participants, the research team developed a collaboration framework enabling better application of sustainable construction practice.

Fig. (1) shows the proposing construction project participant collaboration framework (CPPCF). The essence of the CPPCF is a data exchange hub (DEH), where all project participants share and communicate information embodied in their organizational EMS. Communication and information sharing through the DEH can ensure all project participants act in concert in achieving better environmental performance. Whilst individual organizations have their own EMS, they consistently comply with the EMS principles. Different parties should be motivated to use the DEH to review their performance and to modify wherever necessary their management methodologies. Previous studies suggested four essential components in an EMS [4,17,26,38-44]:

i) Formation of comprehensive environmental policy: environmental policy is to establish a desirable level of environment performance. This established level is used to judge the actual environmental performance of all activities.

ii) Reforming the existing organizational structure for implementing environmental policies: organization structure requires to be established to implement all measures of environmental management. The establishment of such organizational structures give the means to determine responsibilities, authority, lines of communication and resources to implement an EMS. For example, within such organizations, one group or division is responsible to study alternative methods in using tropical wood boards for concrete formwork, and to search for waste disposal methods. A line of communication within organizations should be designed to connect with all concerned parties working on the project.

iii) Laying down specific environmental programmes: an environmental management programme is a detailed plan that specifies specific targets to be met and work instructions and controls to be applied to achieve compliance with environmental policy established within an organization, for example, to reduce construction waste by about $50 \%$.

iv) Reviewing environmental performance and auditing the implementation of the EMS: it is important to undertake periodic audits of environmental performance of construction firms. To audit the environmental performance of construction firms is to measure the progress of a firm's environmental performance. To audit the effectiveness of the EMS is to identify its weaknesses and to provide an essential information feedback to management who can take corrective action.

The CPPCF highlights that all project participants can share the DEH. Individual parties have specific roles and functions. These roles and functions among participants, including government departments, project owners or clients,

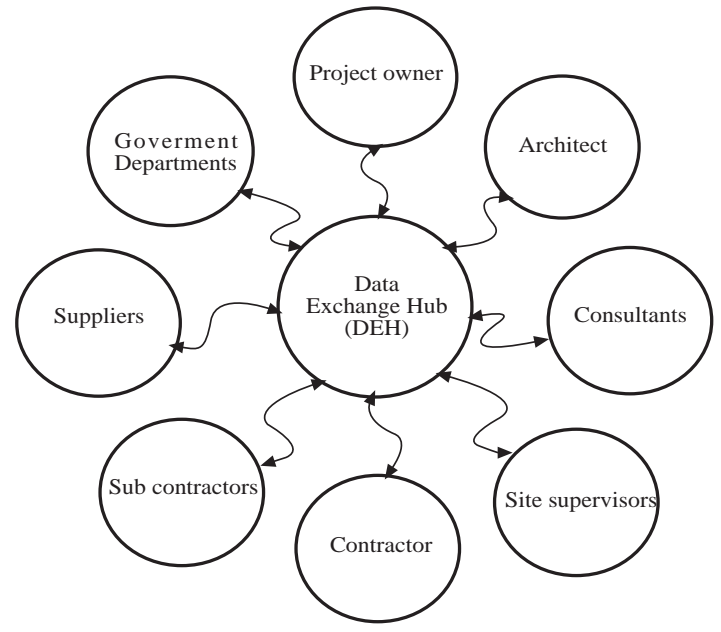

Fig. (1). A construction project participant collaboration framework.

architects, consultants, contractors, suppliers, specialists, tradesmen, and occupiers, must be clearly specified. From the interview discussions, the interviewees noted that without a specific role, a party cannot provide useful contributions. They also suggested the following roles for different parties.

\section{Roles of Government}

To apply sustainable development strategies in a project implementation process, it is expected that the government has to take a leading role. This is consistent with the government's objectives 'to secure sustainable development for our future generations and to take the lead in addressing regional environmental issues' as promised in its policy address [36].

The most important action plan should be to incorporate the EMS to all public projects, and to let legislative councils and the public know its importance and implementation. The public and the legislative councils need to take on the role of monitoring whether the government has done its best for the future of Hong Kong.

The discussions within the research team also suggested that the government should also issue technical guidelines including but not limited to: i) efficient use of space and land; ii) efficient use of energy, reuse and recycling; iii) development of procurement systems allowing for environmental protection costs; iv) reduction of energy demand (embodied energy and operational energy); v) cleaner production rather than 'end-of-pipe' practice; vi) reuse of building materials/components; vii) recycling of materials which cannot be reused directly; viii) proper choice and specification of environment-friendly building materials, and the control of toxic chemicals and dangerous waste; ix) environmental education during study and training; and $\mathrm{x}$ ) collaboration with co-ordinated regulators.

Furthermore, there are various government bureaux and departments involved in massive infrastructure projects. It is highlighted that the Chief Executive should assign a principal official at a secretary or deputy secretary level to lead construction practitioners and be responsible to oversee co- 
ordination and adjustment work in the implementation of government sustainable development strategies. The government departments should also provide assistance and encourage private sector clients to implement the EMS.

\section{Roles of Clients}

Public sector clients have liability to set an example to implement sustainable construction practice. Clients should participate in the whole project process. In the early planning and design stages, clients should provide project briefs and guidelines aiming to improve project sustainability performance. For example, environment-friendly materials and construction methods should be encouraged, lower energy consumption construction structures should be chosen, and certain budget allowances should be made for adopting environmental protection measures across the whole project life cycle.

\section{Roles of Architects and Consultants}

Architects and consultants should incorporate into their work with attributes affecting environmental performance of the project during its construction phase and post-commissioning process throughout design. It is well appreciated that the design has fundamental effects on project performance throughout its life cycle [4,6,38,45-47]. Thus applications of sustainable construction principles into the design process can improve total project sustainability performance. Nevertheless, designers often only focus on technical design parameters such as building types, shapes and directions. This tradition can be improved by encouraging designers to consult specialists or manufacturers on specific aspects with reference to project environmental performance, including energy consumption, life cycle cost, material features, and characteristics and functions of plants and equipment. The interview discussions in this study suggested that project sustainability performance can be improved to a larger extent if designers can collectively consider the following parameters into their designs: i) buildability; ii) life cycle costs; iii) maintainability; iv) repairability; v) upgradeability; vi) choice of materials and their recyclability; vii) construction methods (e.g., adoption of prefabrication, standardization of design); viii) energy efficiency; and ix) users' health and comfort (air, light and view).

\section{Roles of Contractors}

Contractors are key players in contributing to sustainable performance. Contractors should be encouraged to take alternative designs, or supplies, or construction methods if better environmental benefits can be gained [4,6,33,38,46, 49], for example, adopting metal-formwork instead of timber formwork. Contractors should employ well-trained managerial staff to oversee on site environmental aspects, to identify events arising from construction activities and to mitigate their adverse environmental impacts. Pollution and waste control are among the major environmental commitments to contractors. Proper methods must be planned to reduce and to recycle construction waste.

\section{Roles of Suppliers}

Suppliers for construction materials and equipment can also make contributions to attain sustainability performance by supplying environmentally-friendly products. When there is a culture of sustainable construction practice, suppliers are driven by the market to provide products that meet specifications in line with sustainable development principles. New products must have less impact on the environment over the project's life cycle, or otherwise they become obsolete in an environmentally-aware marketplace.

\section{Roles of Users}

Users or owners of construction projects have effects on project sustainability. Project sustainable performance can be improved if the users can efficiently use facilities and maintain them properly.

\section{RECOMMENDATIONS}

To effectively improve sustainable construction, the following are suggested based on the interview discussions:

- To consider sustainable construction implementation at an early project stage;

- To receive initial support from government and clients;

- To mandate sustainable construction practice by government or clients on projects;

- To provide incentive schemes from government and clients in enhancing the implementation of sustainable construction;

- To develop an efficient communication framework among project participants;

- To provide sufficient on site supervision in ensuring optimal sustainable construction practice; and

- To attend training programs to enhance sustainability knowledge.

\section{CONCLUSION}

The implementation of environmental management in construction presents both challenges and opportunities or benefits. This paper suggests that management-related factors are more influential than other factors to the implementation of sustainable construction. The practice in the Hong Kong construction industry shows that the major management-related causes include: (i) the opportunistic culture in the local private property sector to make quick gains; (ii) high labour costs compared with low material cost; (iii) excessively accelerated delivery programmes, leading to inadequate attention being given to environmental considerations; (iv) non-value-adding multi-layered subcontracting and lax site supervision, resulting in ineffective site environmental management; (v) low awareness of environmental issues within construction workers, and reluctance of senior management to commit resources to tackle environmental issues; (vi) failure to efficiently use construction and demolition waste for land reclamation; (vii) insufficient design inputs respecting sustainable development; and (viii) ineffective government encouragement and monitoring for sustainable development. A construction project participant collaboration framework was developed in this study to improve communication among project participants by using a data exchange hub. The study has found that there is good potential for construction participants to make contributions to sustainable development as there are ambitious plans of con- 
struction work and capital projects as shown in Table $\mathbf{4}$ in the foreseeable future. However, these benefits can only be realized if the government can act as a promoter and other construction parties can assume their roles and work together as stakeholders.

\section{ACKNOWLEDGEMENTS}

This research was funded by the Hong Kong Polytechnic University, Hong Kong Special Administration Region, China. This project is supported by the Research Group for Sustainable Development Process (SDP) within Built Environment, which is based in Department of Building and Real Estate of the Hong Kong Polytechnic University. Special thanks to the colleagues in the SDP Research Group.

\section{REFERENCES}

[1] Global Reporting Initiative, http://www.globalreporting.org/index. asp. (Nov. 23, 2005).

[2] Government Construction Clients' Panel Constructing the best government client: achieving sustainability in construction procurement. United Kingdom, Government, 2000.

[3] World Commission on Environment and Developments Our common future. Oxford University Press, 1987.

[4] C. Jasch, "Environmental performance evaluation and indicators". Journal of Cleaner Production, vol. 8, pp.79-88, 2000.

[5] D.Wathey and M. O'Reilly, ISO 14031: a practical guide to developing environmental performance indicators for your business. London: Stationery Office, 2000.

[6] W.L. Kuhre, ISO 14031--environmental performance evaluation (EPE): practice tools and techniques for conducting an environmental performance evaluation. Upper Saddle River, N.J.: Prentice Hall PTR, 1998.

[7] N.H. Apsan, Moving ahead with ISO 14000 - improving environmental management and advancing sustainable development. John Wiley and Sons Ltd, 1997.

[8] R.J. Cole, "Building environmental assessment methods, assessing construction practices", Construction Management and Economics, vol. 18 pp. 949-957, 2000.

[9] C.P. Li, and I.K. Hui, "Environmental impact evaluation model for industrial processes". Environmental Management vol. 27, pp. 729737, 2001.

[10] W. Cai. Sun X-H Adaptive wavelet ADI method: applications and parallelization. Inter. Workshop on Parallel Proc. New Jersey, USA pp. 547-50, 2000,

[11] S.S. Chung and W.H.C. Lo, Evaluating sustainability in waste management: the case of construction and demolition, chemical and clinical wastes in Hong Kong. Resources, Conservation and Recycling vol. 37, pp. 119-145, 2003.

[12] A.R.J. Dainty and R.J. Brooke, Towards improved construction waste minimization: a need for improved supply chain integration? Structure Survey, vol. 22, pp. 20-29, 2004.

[13] J.L. Hao, M.J. Hills and T. Huang, Difficulties and challenges of managing construction and demolition waste in Hong Kong. Proceedings of Third Structural Engineering and Construction Conference. Shunan, Japan, pp. 491-496, 2005.

[14] J.L. Hao and L. Zhang, 2008 Beijing's green olympics: difficulties and challenges in managing construction waste. Proceedings of CRIOCM 2005 International Research Symposium on Advancement of Construction Management and Real Estate. Hangzhou, China: Chinese Research Institute of Construction Management, pp. 660-667, 2005.

[15] C.S. Poon, T.W. Yu and L.H. Ng, A guide for managing and minimizing building and demolition waste. The Hong Kong Polytechnic University, 2001

[16] L.Y. Shen, W.Y.V. Tam, C.M. Tam and D.S. Drew, "Mapping approach for examining waste management in construction sites", Journal of Construction Engineering and Management, vol. 130, 472-481, 2004.
[17] C.M. Tam, W.Y.V. Tam and S.X. Zeng, "Environmental performance evaluation for construction", Building Research and Information, vol 30, pp. 349-361, 2002.

[18] W.Y.V. Tam and C.M. Tam, "Evaluations of existing waste recycling methods: a Hong Kong study", Building and Environment, vol. 41, pp.1649-1660, 2006.

[19] M.M.M. Teo and M. Loosemore, "A theory of waste bahaviour in the construction industry", Journal of Construction Management and Economics, vol. 19, pp. 741-751, 2001

[20] Y.C.R. Tse, "The implementation of EMS in construction firms: case study in Hong Kong", Journal of Environmental Assessment Policy and Management, vol. 3, pp. 177-194, 2001.

[21] Legislative Council, http://www.legislation.gov.hk.

[22] Hong Kong Government, http://www.info.gov.hk. (May, 6, 2007).

[23] C.F. Lam, "The role of engineers in minimising environmental impacts of civil engineering projects", Hong Kong Engineer, pp. 20-23, 1992.

[24] H. Lingard, P. Graham and G. Smithers, "Employee perceptions of the solid waste management system operating in a large Australian contracting organization: implications for company policy implementation", Journal of Construction Management and Economics vol. 18 pp. 383-393, 2000.

[25] D. MacRae, Policy indicators: links between social science and public debate. Chapel Hill, University of North Carolina Press, 1985

[26] L.Y. Shen, and W.Y.V. Tam, "Implementing of environmental management in the Hong Kong construction industry", International Journal of Project Management, vol. 20 pp. 535-543, 2002.

[27] L.Y. Shen, W.Y.V. Tam, C.W.S. Chan and S.Y.J. Kong, "An examination on the waste management practice in the local construction site", Hong Kong Surveyors, vol. 13 pp. 39-48, 2002.

[28] W.Y.V. Tam, C.M. Tam and L.Y. Shen, "Comparing material wastage levels between conventional in-situ and prefabrication construction in Hong Kong", Journal of Harbin Institute of Technology, vol. 11, pp. 548-551, 2004.

[29] O.O. Ugwu, M.M. Kumaraswamy, A. Wong, S.T. Ng, Sustainability appraisal in infrastructure projects (SISAIP): Part 1: development of indicators and computational methods. Automation in Construction, 2005; Article in Press

[30] A. Griffith, Environmental management in construction. The Macmillan Press Ltd, 1994.

[31] A. Griffith, Environmental management systems: an outline guide for construction industry organizations. Department of Building and Real Estate, The Hong Kong Polytechnic University, Hong Kong, 1995.

[32] A. Griffith, "Environmental management in construction process". Construction Papers of CIOB, vol. 75 pp. 3-11, 1997.

[33] International Organization of Standardization, http://www.iso.org/ iso/en/ISOOnline.ftrontpage. (9 February 2006)

[34] Hong Kong Government Financial budget 2006. Hong Kong Government, China, 2006.

[35] Council on sustainable development First sustainable development strategy for Hong Kong. Council on Sustainable Development, Hong Kong government, China, 2004.

[36] D. Tsang, Proactive pragmatic always people first. Legislative Council, Hong Kong government, China, 2006.

[37] Hong Kong Special Administrative Region Government The 200708 budgets, Section IV, Appendix B. Hong Kong Special Administrative Region Government, China, 2007.

[38] Clayton Group Services, http://www.claytongrp.com. (9 June, 2001).

[39] D. Crawley, and I. Aho, "Building environmental assessment methods: applications and development trends". Building Research and Information, vol. 27, pp. 300-308, 1999.

[40] Hong Kong Government - Environmental Protection Department Environmental Report 2006. Environmental Protection Department, Hong Kong government, 2006.

[41] R. Morledge and F. Jackson, "Reducing environmental pollution caused by construction plant", Environmental Management and Health, vol. 12, pp. 191-206, 2001.

[42] B. Polster, B. Peuportier, I. Sommereux, P. Pedregal, C. Gobin and E. Durand, "Evaluation of the environmental quality of buildings towards a more environmentally conscious design", Solar Energy, vol. 57, pp. 219-230, 1996. 
[43] X. Ren, "Developing of environmental performance indicators for textile process and product". Journal of Cleaner Production, vol. 8, pp. 473-481, 2000.

[44] C.M. Tam, Z.M. Deng and S.X. Zeng, "Evaluation of construction methods and performance for high rise public housing construction in Hong Kong", Building and Environment, vol. 37, pp. 983-991, 2002.

[45] C. Bachas and T.N. Tomaras, "Ribbons around Mexican hats," Nuclear Physics B, vol. B428, pp. 209-20, 1994.

[46] M. Benneth and P. James, The evolution of integrated environmental performance evaluation and reporting at Baxter international. Sustainable measures evaluation and reporting of environ- mental and social performance: Sheffield, Greenleaf publication, 1999.

[47] M. Benneth and P. James, ISO 14031 and the future of environmental performance evaluation. Sustainable measures evaluation and reporting of environmental and social performance: Sheffield, Greenleaf publication, 1999.

[48] R.D. Meyer. Conducting environmental performance evaluation using environmental performance indicators. Clayton Group Services, 2001.

[49] T. Tibor, ISO 14000: a guide to the new environmental management standards. Chicago: Irwin Professional Publication, 1996.

Received: March 31, 2008

Revised: May 23, 2008

Accepted: June 01, 2008

(C) Shen et al.; Licensee Bentham Open.

This is an open access article distributed under the terms of the Creative Commons Attribution License (http://creativecommons.org/license/by/2.5/), which permits unrestrictive use, distribution, and reproduction in any medium, provided the original work is properly cited. 